\title{
Mechanical and Failure Criteria of Air-Entrained Concrete under Triaxial Compression Load after Rapid Freeze-Thaw Cycles
}

\author{
Feng-kun Cui, ${ }^{1}$ Huai-shuai Shang, ${ }^{2}$ Tie-jun Zhao, ${ }^{2}$ Guo-xi Fan, ${ }^{3}$ and Guo-sheng Ren ${ }^{2}$ \\ ${ }^{1}$ School of Highway, Chang'an University, Xian, Shaanxi 710064, China \\ ${ }^{2}$ School of Civil Engineering, Qingdao University of Technology, Qingdao, Shandong 266033, China \\ ${ }^{3}$ School of Engineering, Ocean University of China, Qingdao, Shandong 266100, China \\ Correspondence should be addressed to Feng-kun Cui; 929599342@qq.com and Huai-shuai Shang; shanghuaishuai@aliyun.com
}

Received 19 November 2016; Accepted 24 January 2017; Published 13 February 2017

Academic Editor: Paulo M. S. T. De Castro

Copyright (C) 2017 Feng-kun Cui et al. This is an open access article distributed under the Creative Commons Attribution License, which permits unrestricted use, distribution, and reproduction in any medium, provided the original work is properly cited.

\begin{abstract}
The experiment study on the air-entrained concrete of $100 \mathrm{~mm}$ cubes under triaxial compression with different intermediate stress ratio $\alpha_{2}=\sigma_{2}^{D}: \sigma_{3}^{D}$ was carried out using a hydraulic-servo testing system. The influence of rapid freeze-thaw cycles and intermediate stress ratio on the triaxial compressive strength $\sigma_{3}^{D}$ was analyzed according to the experimental results, respectively. The experimental results of air-entrained concrete obtained from the study in this paper and the triaxial compression experimental results of plain concrete got through the same triaxial-testing-system were compared and analyzed. The conclusion was that the triaxial compressive strength is greater than the biaxial and uniaxial compressive strength after the same rapid freeze-thaw cycles, and the increased percentage of triaxial compressive strength over biaxial compressive strength or uniaxial compressive strength is dependent on the middle stress. The experimental data is useful for precise analysis of concrete member or concrete structure under the action complex stress state.
\end{abstract}

\section{Introduction}

In cold regions, such as northern China, Russia, Canada, and northern Europe, the performance (e.g., strength, deformation and elasticity modulus) deterioration of concrete applied in practical engineering can be caused by the action of rapid freeze-thaw cycles. Özgan and Serin [1] investigated the effect of freeze-thaw cycles on asphalt concrete materials according to Marshall stability values and ultrasonic velocity and so forth. The value of fracture parameters of lightweight concrete after different freeze-thaw cycles was determined through a three-point bending test in [2]. The weight loss, pulse velocity, and resonance frequency of silica fume concrete after the action of freeze-thaw cycles were reported in [3]. The influence of freeze-thaw cycles on the behavior (compressive strength, weight loss, and relative pulse velocity) of concrete with synthetic fibre additions was studied in [4]. The experimental results show that the freeze-thaw cycles can cause the degradation of the strength and deformation properties of asphalt concrete, lightweight aggregate concrete, silica fume concrete, and so forth.

Several kinds of mechanisms, such as "microscopic ice lens growth" [5] and "hydraulic pressure" [6] could be used to explain the frost damage in concrete. Some researches demonstrated that the inner structures and material properties of concrete have more significant effect on this damage degree than the external environment [7-9]. And the internal structure of concrete may be affected by the frost damage caused by the inner pressure and the associated micro cracks. Based on this, air-entrained agent is added to the concrete to make air-entrained concrete. One of the advantages of air-entrained concrete is its greater resistance to damage caused by freeze-thaw cycles [10-12] which make it especially suitable in the construction of dam, long span bridges, and offshore oil platforms in cold environment. So far, airentrained concrete [13] has been widely used in the field 
TABLE 1: Mix proportions of air-entrained concrete.

\begin{tabular}{|c|c|c|c|c|c|c|}
\hline $\mathrm{w} / \mathrm{c}$ & Cement $\left(\mathrm{kg} / \mathrm{m}^{3}\right)$ & Sand $\left(\mathrm{kg} / \mathrm{m}^{3}\right)$ & Coarse Aggregate $\left(\mathrm{kg} / \mathrm{m}^{3}\right)$ & Water $\left(\mathrm{kg} / \mathrm{m}^{3}\right)$ & Air-entraining agents $\left(\mathrm{kg} / \mathrm{m}^{3}\right)$ & Air content $(\%)$ \\
\hline 0.40 & 412.67 & 586.83 & 1186.00 & 164.30 & 1.03 & 5.80 \\
\hline
\end{tabular}

of hydraulic engineering and civil engineering. However, a lot of experimental tests are carried out to determine the freeze-thaw durability of different type concrete, while, for air-entrained concrete, the research is still comparatively rare. Pheeraphan and Leung [14] studied the freeze-thaw resistance of microwave cured air-entrained concrete. According to the test results of Pheeraphan and Leung, the freeze-thaw durability of high w/c concrete will be impaired by microwave curing. Shang et al. [15] investigated the weight loss, relative dynamic modulus of elasticity, tensile strength, compressive strength, cubic compressive strength, and cleavage strength of air-entrained concrete after different freeze-thaw cycles. And it can be seen from $[14,15]$, for air-entrained concrete or other types of concrete, that most of the previous researchers mainly focused their attention on the dynamic elastic modulus, weight loss, flexural strength, and uniaxial compression strength after different freeze-thaw cycles. Meanwhile, in civil engineering, it can be well-known that concrete materials in member of structure (e.g., shear walls, thin shells, and slabs) are essentially in a complex stress state: such as biaxial compression, triaxial tension-tension-compression, triaxial compression [16-19]. For refined calculation, the behavior of concrete materials under a stress state of multiaxial loads should be examined carefully. The mechanical performance of plain concrete under biaxial and triaxial compression was studied after freeze-thaw cycles [20-22]. Wang and Song [23] investigated the failure criterion of the haydite concrete under triaxial loading. The strength criterion of lightweight aggregate concrete under multiaxial loads was also studied based on the unified twin-shear strength theory [24].

According to experimental results in the literature, it has been realized that although a large number of test data are available regarding the triaxial compression behavior of plain concrete and some special concrete, very little information on the behavior of air-entrained concrete under triaxial stress state can be found, especially the behavior of air-entrained concrete under triaxial compressive loads after the action of different rapid freeze-thaw cycles. Many literatures [1-4, 912, 19-21] illustrated that the strength and peak strain in concrete are influenced significantly by the inner damage caused by freeze-thaw cycles. Hanjari [25] pointed out that the results obtained from the undamaged concrete can not be applied directly for the frost-damaged concrete.

In order to better understand and predict the performance of structure and member made with air-entrained concrete material, the mechanical properties of air-entrained concrete should be figured out. Shang [26] investigated the triaxial compression behavior of air-concrete with stress ratio $\sigma_{2}^{D}: \sigma_{3}^{D}=1.00: 1.00$. The experiment on strength behavior of air-entrained concrete under triaxial compression load with $\sigma_{1}^{D}: \sigma_{3}^{D}=0.10: 1.00$ after rapid freeze-thaw cycles was carried out. Results obtained from the experimental studies will be used to develop a simple relationship between mechanical behavior and number of rapid freeze-thaw cycles for airentrained concrete. The relationship can be used as input to computer programs to analyze the behavior of air-entrained concrete structural members subjected to different rapid freeze-thaw cycles.

\section{Experimental Program}

2.1. Materials and Mix Proportions. The $42.5^{\#}$ Ordinary Portland cement (the compressive strength should reach 22.0 $\mathrm{MPa}$ and 42.5 $\mathrm{MPa}$ at days 3 and 28; the flexural strength should reach $4.0 \mathrm{MPa}$ and $6.5 \mathrm{MPa}$ at days 3 and 28), tap water, river sand (fineness modulus was 2.6), crushed natural stone aggregate (diameter ranges from $5 \mathrm{~mm}$ to $20 \mathrm{~mm}$ ), and air-entrained admixture (rosin soap air-entraining agent was used) were used in this experimental study. The proportions by weight of cement: water: sand: coarse aggregate are $1: 0.4: 1.42: 2.87$. The mixing proportions in this experiment were given in Table 1 . The air content of the concrete mixture was $5.8 \%$ after mixing. The compressive strength of 28 days is 25.64 MPa.

2.2. Specimen and Testing Programs. In this experiment study, horizontal forced action mixer with $0.1 \mathrm{~m}^{3}$ was used to elaborate the mixture. The following mixing procedure was used: first, fine aggregate, coarse aggregate, and cement were put into the mixer and the components were mixed for 1 minute; then, tap water was added and continued to stir for 2 3 minute; next, the fresh concrete material was cast in cubical molds with size $100 \mathrm{~mm} \times 100 \mathrm{~mm} \times 100 \mathrm{~mm}$ and a vibrating table with size $1 \mathrm{~m} \times 1 \mathrm{~m}$ was used to compact concrete. After the fresh concrete was mixed, the air content was measured with air-content measuring instrument. At the same time, freshly cast specimens were kept in the molds for 24 hours. Finally, they were demoulded and stored in a curing room which can keep 95 percent relative humidity and the temperature of $20 \pm 3^{\circ} \mathrm{C}$. At 24 days of age, some air-entrained concrete specimens were taken out from the curing room and immersed in water for 4 days.

According to "the test method of long-term and durability on ordinary concrete" $[21,27]$, the rapid freeze-thaw tests were performed in a rapid freeze-thaw apparatus at 28 days of age for concrete specimen. In a single rapid freeze-thaw cycle, the center temperature of the specimens should cool from $6^{\circ} \mathrm{C}$ to $-15^{\circ} \mathrm{C}$ and then warm to $6^{\circ} \mathrm{C}$ during about $2.5-$ $3 \mathrm{~h}$. The temperature of the concrete specimens was measured and controlled by a Pt sensor embedded in the center of concrete specimen. And the test is similar to the ASTMC 666, "Standard Test Method for Resistance of Concrete to Rapid Freezing and Thawing" [28]. In a single cycle according to 


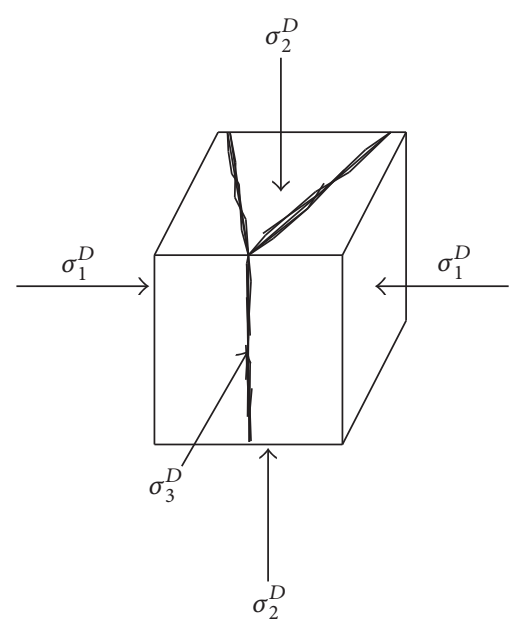

(a) Loading direction and surface crack of specimen under triaxial compression load

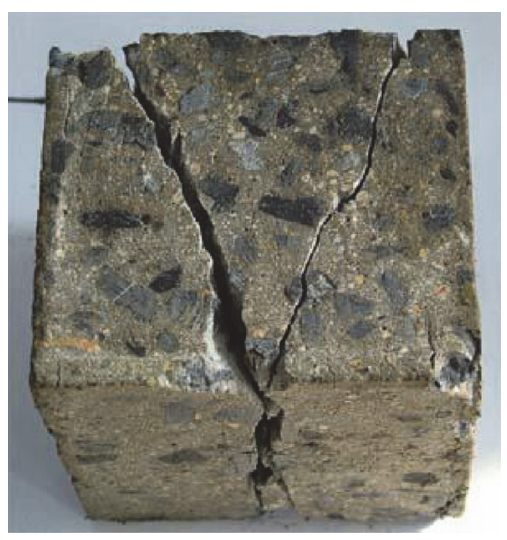

(b) Failure mode and surface cracks of airentrained concrete under triaxial compression after rapid freeze-thaw cycles

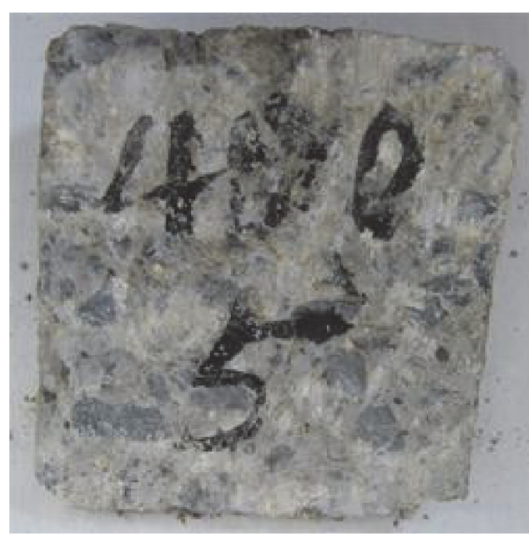

(c) Fracture surface of air-entrained concrete under triaxial compression load after 400 rapid freeze-thaw cycles

FIGURE 1: The failure mode and fracture surface of air-entrained concrete specimen after different freeze-thaw cycles.

ASTMC 666, the temperature of the specimens cools from 4.4 to $-17.8^{\circ} \mathrm{C}$ and then warms to $4.4^{\circ} \mathrm{C}$ within 2 to $5 \mathrm{~h}$.

And the triaxial compression experiment was carried out in a triaxial-testing-system [21, 29]. The stress ratios were $\alpha=\sigma_{1}^{D}: \sigma_{2}^{D}: \sigma_{3}^{D}=0.10: 0.25: 1.00,0.10: 0.50: 1.00$, $0.10: 0.75: 1.00$, and $0.10: 1.00: 1.00$. The relationship of principal compressive stresses was expressed as $\sigma_{1}^{D} \leq \sigma_{2}^{D} \leq$ $\sigma_{3}^{D}$ (compression stress denoted as positive). The friction between loading plate of testing machine and surface of concrete specimen will affect the experimental results; in order to eliminate the influence of friction, the frictionreducing pads [30] (consisting of three plastic membranes with three layers of butter between them) were used which were placed between the specimen and the loading plate.

\section{Results and Discussions}

3.1. Failure Modes. Figure 1(a) gives the triaxial compression loading direction for air-entrained concrete specimens. The triaxial compression failure mode and surface crack of air-entrained concrete specimen after different freeze-thaw cycles were given in Figure 1(b).

A gradual failure was observed in the triaxial compression experiment on air-entrained concrete specimens after different freeze-thaw cycles. The failure surfaces are "neat surfaces" and cracks pass through the "broken aggregate." The failure surface contained fractures through both cement mortar and coarse aggregate. A typical fracture surface of an air-entrained concrete specimen is shown in Figure 1(c).

Under triaxial compression load with stress ratios $\alpha=\sigma_{1}^{D}: \sigma_{2}^{D}: \sigma_{3}^{D}=0.10: 0.25: 1.00, \quad 0.10: 0.50: 1.00$, $0.10: 0.75: 1.00$, and $0.10: 1.00: 1.00$, the failure mode of the specimens was slant-shear failure, which was caused by the splitting tensile strain along $\sigma_{1}^{D}$ direction. The angle between the direction of $\sigma_{3}^{D}$ and the crack was about $20^{\circ} \sim 30^{\circ}$.
There were two cracks on $\sigma_{2}^{D}$ surfaces; the number of cracks on the $\sigma_{3}^{D}$ surfaces was one or two, respectively.

Under triaxial compression load with stress ratios $\alpha=$ $\sigma_{1}: \sigma_{2}: \sigma_{3}=0.05: 1: 1,0.1: 1: 1,0.15: 1: 1$, and $0.2: 1: 1$ in [26], the failure mode of the specimens of air-entrained concrete specimen was parallel plate-type fragments mode and slantshear failure mode; the angle between the crack and the direction of $\sigma_{3}$ was about $20^{\circ} \sim 30^{\circ}$ when the stress ratios were $\alpha=0.1: 1: 1,0.15: 1: 1$, and $0.2: 1: 1$; the angle between the crack and the direction of $\sigma_{3}$ was about $10^{\circ} \sim 20^{\circ}$ when $\alpha=$ $0.05: 1: 1$; and parallel plate-type fragments were formed on the surface of $\sigma_{2}$ and $\sigma_{3}$ under triaxial compression load with stress ratios $\alpha=\sigma_{1}: \sigma_{2}: \sigma_{3}=0: 1.00: 1.00$. According to the experiment results of plain concrete conducted on the same triaxial-testing-system with this paper [20], the splitting cracks in slice shapes were formed on surface of $\sigma_{2}$ and $\sigma_{3}$ under triaxial compression load with stress ratios $\alpha=\sigma_{1}: \sigma_{2}: \sigma_{3}=0.1: 1: 1$, and the slant-shear cracks are in good agreement with experimental results obtained in this paper when triaxial compression stress ratios are $\alpha=$ $\sigma_{1}: \sigma_{2}: \sigma_{3}=0.1: 0.25: 1.0 ; 0.1: 0.5: 1.0 ; 0.1: 0.75: 1.0$. Reference [20] studied triaxial compression strength of plain concrete through experiment, and three failure modes were observed in this experiment, which are (1) splitting cracks in slice shapes, (2) splitting cracks in column shapes, and (3) flow and deformation.

3.2. Experimental Results. Table 2 listed the test results of air-entrained concrete under triaxial compression load with different intermediate stress ratio $\alpha_{2}=\sigma_{2}^{D}: \sigma_{3}^{D}$ after rapid freeze-thaw cycles. The compressive stresses $\sigma_{1}^{D}, \sigma_{2}^{D}$, and $\sigma_{3}^{D}$ were got through dividing compressive loads with loading area $\left(0.01 \mathrm{~m}^{2}\right) \cdot \sigma_{\text {oct }}^{D}$ and $\tau_{\text {oct }}^{D}$ are the normal stress and the shear stress in octahedral stress space after different freeze-thaw cycles $[20,31]$ which can be computed from 
TABLE 2: Experimental results of air-entrained concrete under triaxial compression after rapid freeze-thaw cycles (MPa).

\begin{tabular}{|c|c|c|c|c|c|c|c|c|}
\hline Freeze-thaw cycles & $\alpha$ & $\sigma_{1}^{D}$ & $\sigma_{2}^{D}$ & $\sigma_{3}^{D}$ & $\sigma_{\text {oct }}^{D}$ & $\tau_{\mathrm{oct}}^{D}$ & $\sigma_{\mathrm{oct}}^{D} / f_{c}$ & $\overline{\tau_{\mathrm{oct}}^{D} / f_{c}}$ \\
\hline \multirow{4}{*}{0} & $0.1: 0.25: 1$ & 10.45 & 24.38 & 95.81 & 43.55 & 37.39 & 1.70 & 1.46 \\
\hline & $0.1: 0.5: 1$ & 11.84 & 52.92 & 105.39 & 56.72 & 38.29 & 2.21 & 1.49 \\
\hline & $0.1: 0.75: 1$ & 9.96 & 69.30 & 92.35 & 57.20 & 34.71 & 2.23 & 1.35 \\
\hline & $0.1: 1: 1$ & 10.04 & 85.01 & 85.22 & 60.09 & 35.39 & 2.34 & 1.38 \\
\hline \multirow{4}{*}{100} & $0.1: 0.25: 1$ & 10.45 & 24.29 & 95.40 & 43.38 & 37.22 & 1.69 & 1.45 \\
\hline & $0.1: 0.5: 1$ & 10.98 & 49.92 & 99.60 & 53.5 & 36.27 & 2.09 & 1.41 \\
\hline & $0.1: 0.75: 1$ & 9.95 & 66.92 & 89.20 & 55.36 & 33.37 & 2.16 & 1.30 \\
\hline & $0.1: 1: 1$ & 10.13 & 84.51 & 84.75 & 59.80 & 35.12 & 2.33 & 1.37 \\
\hline \multirow{4}{*}{200} & $0.1: 0.25: 1$ & 9.49 & 21.62 & 84.95 & 38.69 & 33.09 & 1.51 & 1.29 \\
\hline & $0.1: 0.5: 1$ & 9.32 & 42.45 & 84.48 & 45.42 & 30.76 & 1.77 & 1.20 \\
\hline & $0.1: 0.75: 1$ & 8.82 & 59.55 & 79.46 & 49.28 & 29.74 & 1.92 & 1.16 \\
\hline & $0.1: 1: 1$ & 8.77 & 73.12 & 73.33 & 51.74 & 30.38 & 2.02 & 1.19 \\
\hline \multirow{4}{*}{300} & $0.1: 0.25: 1$ & 7.15 & 16.20 & 63.46 & 28.94 & 24.69 & 1.13 & 0.96 \\
\hline & $0.1: 0.5: 1$ & 8.22 & 37.14 & 73.92 & 39.76 & 26.89 & 1.553 & 1.05 \\
\hline & $0.1: 0.75: 1$ & 8.58 & 57.09 & 76.09 & 47.25 & 28.42 & 1.843 & 1.11 \\
\hline & $0.1: 1: 1$ & 7.87 & 66.10 & 66.33 & 46.77 & 27.50 & 1.823 & 1.07 \\
\hline \multirow{4}{*}{400} & $0.1: 0.25: 1$ & 6.66 & 15.41 & 60.51 & 27.53 & 23.59 & 1.07 & 0.92 \\
\hline & $0.1: 0.5: 1$ & 7.49 & 34.22 & 68.25 & 36.65 & 24.86 & 1.43 & 0.97 \\
\hline & $0.1: 0.75: 1$ & 6.92 & 45.52 & 60.70 & 37.71 & 22.64 & 1.47 & 0.88 \\
\hline & $0.1: 1: 1$ & 7.57 & 59.55 & 59.97 & 42.36 & 24.60 & 1.65 & 0.96 \\
\hline
\end{tabular}

the following: $\tau_{\text {oct }}^{D}=(1 / 3)\left(\sigma_{1}^{D}+\sigma_{2}^{D}+\sigma_{3}^{D}\right)$ and $\sigma_{\text {oct }}^{D}=$ $(1 / 3) \sqrt{\left(\sigma_{1}^{D}-\sigma_{2}^{D}\right)^{2}+\left(\sigma_{2}^{D}-\sigma_{3}^{D}\right)^{2}+\left(\sigma_{3}^{D}-\sigma_{1}^{D}\right)^{2}}$.

3.2.1. Effect of Rapid Freeze-Thaw Cycles on Peak Stress $\sigma_{3}^{D}$. The effect of rapid freeze-thaw cycles on strength of airentrained concrete under triaxial compression load with different stress ratio was depicted in Figure 2. Table 3 demonstrates the loss of ultimate strength of air-entrained concrete under triaxial compression with increasing the rapid freeze-thaw cycles. It can be got from Figure 2 and Table 3 that the principal stress $\sigma_{3}^{D}$ decreases as number of rapid freeze-thaw cycles increases. The reduction of triaxial compression strength of air-entrained concrete is slower than that of uniaxial and biaxial compression strength as number of rapid freeze-thaw cycles increases. After the action of 200 rapid freeze-thaw cycles, the uniaxial compression strength and biaxial equal compression strength decreased to 81.0 and 83.1 percent of those prior to the rapid freezethaw cycles, respectively; meanwhile, under the action of triaxial compression with stress ratio $\alpha=0.10: 1.00: 1.00$, the strength decreased to 86.05 percent of that prior to the rapid freeze-thaw cycles. After the action of 200 rapid freeze-thaw cycles, the strength under triaxial compression with stress ratios $\alpha=0.10: 0.25: 1.00,0.10: 0.50: 1.00,0.10: 0.75: 1.00$, and $0.10: 1.00: 1.00$ varied from $80.16 \%$ to $88.67 \%$ of initial value prior to freeze-thaw cycles.

For air-entrained concrete specimen under triaxial compression with stress ratios $\alpha=0.05: 1.00: 1.00,0.10: 1.00: 1.00$, $0.15: 1.00: 1.00$, and $0.20: 1.00: 1.00$ [26], the strength after the action of 200 rapid freeze-thaw cycles varied from $83.15 \%$ to $93.82 \%$ of that prior to rapid freeze-thaw cycles. The

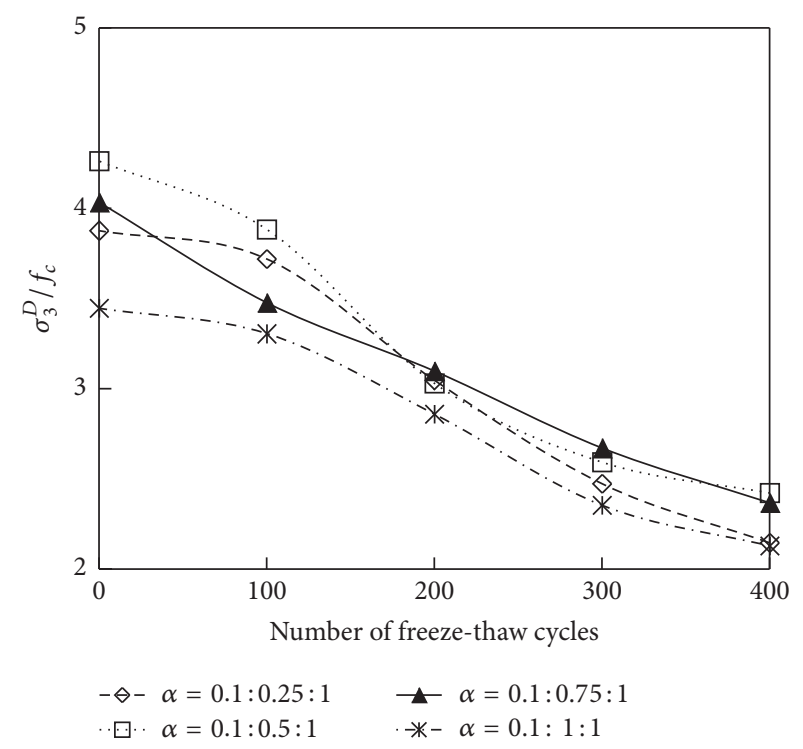

FIGURE 2: Effect of rapid freeze-thaw cycles on triaxial compressive strength under different intermediate stress ratio.

effect of rapid freeze-thaw cycles on strength of air-entrained concrete under triaxial compression load with stress ratios $0: 1.0: 1.0,0.05: 1.0: 1.0,0.15: 1.0: 1.0$, and $0.2: 1.0: 1.0$ was given in Table 3 . The effect of rapid freeze-thaw cycles on strength of plain concrete under triaxial compression load with stress ratios $\alpha=0.10: 0.25: 1.00,0.10: 0.50: 1.00$, $0.10: 0.75: 1.00$, and $0.10: 1.00: 1.00$ was given in Table 4 as well. 
TABLE 3: Loss of ultimate strength of air-entrained concrete under triaxial compression load with rapid freeze-thaw cycles (\%).

\begin{tabular}{lcccc}
\hline Stress ratio & \multicolumn{3}{c}{ Number of rapid freeze-thaw cycles } \\
& 100 & 200 & 300 & 400 \\
\hline $0.1: 0.25: 1.0$ & 99.57 & 88.67 & 66.24 & 70.14 \\
$0.1: 0.50: 1.0$ & 94.51 & 80.16 & 82.39 & 63.16 \\
$0.1: 0.75: 1.0$ & 96.59 & 86.04 & 77.83 & 65.73 \\
$0.1: 1.0: 1.0$ & 99.45 & 86.05 & 65.02 & 70.37 \\
Uniaxial compression & 90.36 & 81.05 & 68.50 & 57.31 \\
Biaxial equal compression & 92.09 & 83.15 & 68.50 & 56.67 \\
$0: 1.0: 1.0$ in [26] & 92.09 & 83.15 & 75.67 & 68.67 \\
$0.05: 1.0: 1.0$ in [26] & 94.32 & 89.54 & 89.12 & 81.00 \\
$0.15: 1.0: 1.0$ in [26] & 96.63 & 93.82 & 86.08 & 86.61 \\
$0.2: 1.0: 1.0$ in [26] & 98.29 & 91.88 & & \\
\hline
\end{tabular}

TABLE 4: Loss of ultimate strength of plain concrete under triaxial compression with rapid freeze-thaw cycles (\%).

\begin{tabular}{lccc}
\hline \multirow{2}{*}{ Stress ratio } & \multicolumn{3}{c}{ Number of rapid freeze-thaw cycles } \\
& 25 & 50 & 75 \\
\hline $0.1: 0.25: 1.0$ & 95.88 & 89.13 & 80.38 \\
$0.1: 0.50: 1.0$ & 96.68 & 93.30 & 90.65 \\
$0.1: 0.75: 1.0$ & 98.20 & 93.18 & 87.04 \\
$0.1: 1.0: 1.0$ & 96.50 & 92.80 & 89.38 \\
\hline
\end{tabular}

For plain concrete specimens of $100 \mathrm{~mm}$ cube, the mechanical properties under the action of uniaxial compression load, biaxial compression load, and triaxial compression load with stress ratios $\alpha=0.10: 0.25: 1.00,0.10: 0.50: 1.00$, $0.10: 0.75: 1.00$, and $0.10: 1.00: 1.00$ after $0,25,50$, and 75 freeze-thaw cycles have been investigated by Shang et al. [20]. According to the information in [20], the same conclusion that the reduction of triaxial compressive strength is slower than that of uniaxial and biaxial compression strength with increasing the number of rapid freeze-thaw cycles was got. To illustrate, after the action of 75 rapid freeze-thaw cycles, compared with the initial strength of plain concrete under triaxial compression load with stress ratio $\alpha=0.10: 1.00: 1.00$ prior to the rapid freeze-thaw cycles, the triaxial compressive strength decreased to 89.4 percent of initial value, while the biaxial equal compression strength and uniaxial compression strength decreased to 78.3 and 63.4 percent of initial value prior to the rapid freeze-thaw cycles, respectively. And, for plain specimen under triaxial compression with stress ratios $\alpha=0.10: 0.25: 1.00,0.10: 0.50: 1.00,0.10: 0.75: 1.00$, and $0.10: 1.00: 1.00$ [20], the strength after the action of 75 rapid freeze-thaw cycles varied from $80.38 \%$ to $90.65 \%$ of initial value prior to rapid freeze-thaw cycles. It can be obtained from Table 3 that the effect of rapid freezethaw cycles on mechanical behavior (triaxial compression strength, biaxial compression strength, or uniaxial compression strength) of air-entrained concrete is much greater than that on mechanical behavior of plain concrete. That is, compared with plain concrete, air-entrained concrete is more applicable to be used in the cold regions.

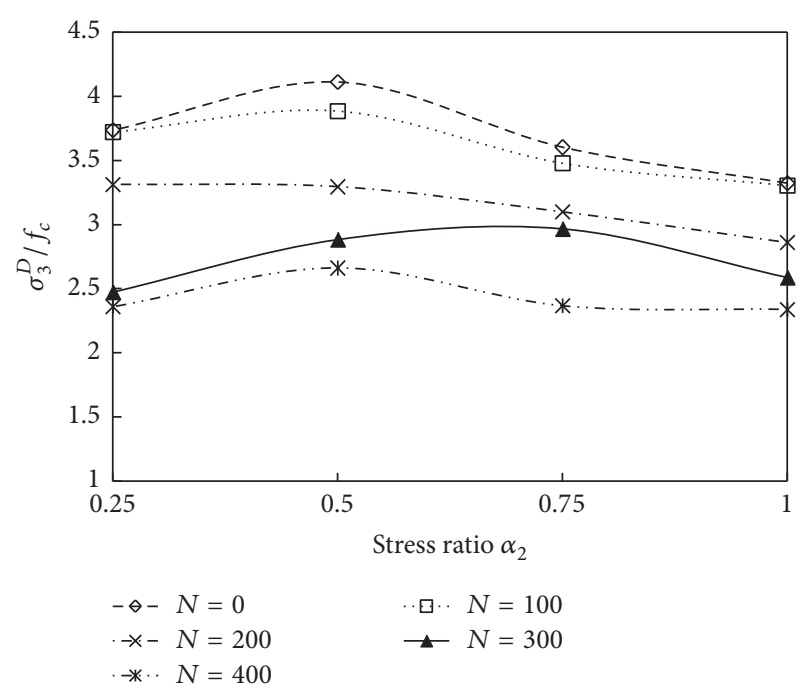

FIGURE 3: Influence of middle stress ratio $\alpha_{2}$ on triaxial compressive strength after rapid freeze-thaw cycles.

3.2.2. Effect of Stress Ratio $\alpha_{2}$ on Peak Stress $\sigma_{3}^{D}$. According to the experiment result of air-entrained concrete after the same rapid freeze-thaw cycles listed in Table 2, compared with the uniaxial compression strength, the triaxial compression strength improved greatly due to the action of lateral compression stress. Under the action of triaxial compression load, the increasing percentage of ultimate strength after different freeze-thaw cycles compared with uniaxial compression strength prior to freeze-thaw cycles is shown in Figure 3. Just as demonstrated in Figure 3, the triaxial compressive strength with all stress ratios is greater than the uniaxial compressive strength after the same rapid freeze-thaw cycles. And the improved value will change with the change of stress ratio of triaxial compression. After the action of 0,100 , and 400 rapid freeze-thaw cycles, the triaxial compressive strength is largest when the stress ratio was equal to $0.10: 0.50: 1.00$. Consistent with this, for plain concrete under triaxial compression, the same conclusion was got in [20]. According to the experimental results in [20], for plain concrete subjected to $0,25,50$, and 75 rapid freeze-thaw cycles, the improved value 
TABLE 5: Increased percentage of triaxial compression strength over uniaxial compression strength (\%).

\begin{tabular}{|c|c|c|c|c|c|c|c|c|c|}
\hline \multirow{3}{*}{ Stress ratio } & \multicolumn{9}{|c|}{ Number of rapid freeze-thaw cycles } \\
\hline & \multicolumn{5}{|c|}{ Test results of air-entrained concrete } & \multicolumn{4}{|c|}{ Test results of plain concrete in [16] } \\
\hline & 0 & 100 & 200 & 300 & 400 & 0 & 25 & 50 & 75 \\
\hline $0.1: 0.25: 1.0$ & 3.74 & 4.11 & 3.60 & 3.32 & 3.74 & 3.94 & 3.78 & 3.51 & 3.16 \\
\hline $0.1: 0.50: 1.0$ & 3.72 & 3.88 & 3.48 & 3.31 & 3.72 & 4.15 & 4.01 & 3.87 & 3.76 \\
\hline $0.1: 0.75: 1.0$ & 3.31 & 3.29 & 3.10 & 2.86 & 3.31 & 3.71 & 3.64 & 3.45 & 3.23 \\
\hline $0.1: 1.0: 1.0$ & 2.48 & 2.88 & 2.97 & 2.59 & 2.48 & 3.28 & 3.16 & 3.04 & 2.93 \\
\hline
\end{tabular}

TABLE 6: The value of $a_{1}, a_{2}, a_{3}$, and $r$.

\begin{tabular}{lcccc}
\hline \multicolumn{5}{c}{ Stress ratio } \\
& $0.05: 1.0: 1$ & $0.1: 0.25: 1$ & $0.1: 0.5: 1$ & $0.1: 0.75: 1$ \\
\hline$a_{1}$ & 0.1902 & -0.0051 & -0.0739 & 0.0490 \\
$a_{2}$ & 0.5250 & 0.8608 & 0.7091 & 0.5842 \\
$a_{3}$ & -0.0161 & -0.0004 & 0.0077 & -0.0061 \\
$r$ & 0.998 & 1.00 & 1.00 & 1.00 \\
\hline
\end{tabular}

of triaxial compressive strength over uniaxial compression strength is largest when triaxial compression stress ratio $\alpha=$ $0.10: 0.50: 1.00$.

For air-entrained concrete under triaxial compression with different stress ratios prior to rapid freeze-thaw cycles, the ratio between triaxial compression strength and uniaxial compressive strength varied from 2.48 to 3.74. And, after the action of 300 rapid freeze-thaw cycles, the ratio between triaxial compression strength and uniaxial compression strength varied from 2.59 to 3.32 .

Meanwhile, for plain concrete under triaxial compression load with different stress ratios prior to rapid freeze-thaw cycles [20], the ratio between triaxial compression strength and uniaxial compression strength varied from 3.28 to 4.15 , and, after the action of 50 rapid freeze-thaw cycles, the ratio varied to be from 3.04 to 3.87 times the uniaxial compression strength. The increased percentage of triaxial compression strength over uniaxial compression strength for air-entrained-concrete and plain concrete is shown in Table 5.

3.3. Failure Criteria. The failure criteria expressed in shear stress $\tau_{\text {oct }}$ and normal stress $\sigma_{\text {oct }}$ in octahedral stress space $[20,31]$ can be proposed as follows:

$$
\frac{\tau_{\mathrm{oct}}}{f_{c}}=a_{1}+a_{2} \frac{\sigma_{\mathrm{oct}}}{f_{c}}+a_{3} N
$$

where $a_{1}, a_{2}$, and $a_{3}$ are the regress parameters, respectively, $N$ is the number of rapid freeze-thaw cycles, the correlative coefficient $r$ can be got through regression of the test results of air-entrained concrete under triaxial compression load after the action of different rapid freeze-thaw cycles, and the values of $a_{1}, a_{2}, a_{3}$, and $r$ were given in Table 6 .

Figure 4 gives the testing results of air-entrained concrete under triaxial compression load and the computed results obtained according to (1). Through comparing the test results

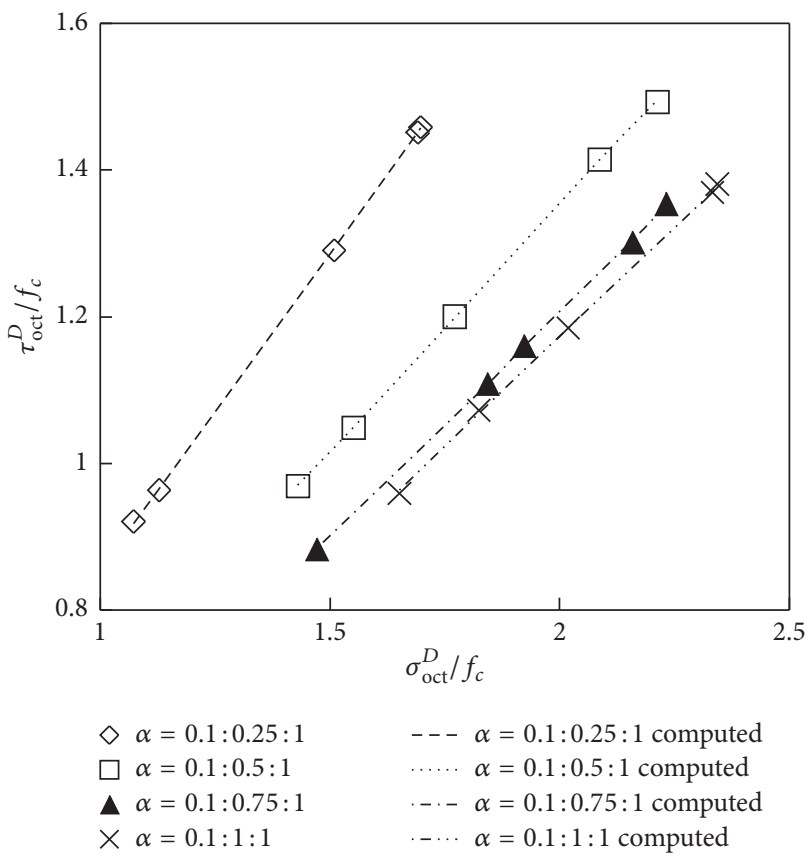

Figure 4: Test results of triaxial compressive strength after rapid freeze-thaw cycles in octahedral stress space.

with the computed results, it can be seen from Figure 2 that they are in good agreement.

3.4. Discussion. The deterioration of concrete material will be caused by the action of rapid freeze-thaw cycles. Compared with plain concrete, the form of the bubble in air-entrained concrete is more uniform due to the introduction of airentraining agent. Under the effect of rapid freeze-thaw cycles, the existence of the bubble could relieve the internal expansion pressure caused when the water freezes. Then, after the action of same rapid freeze-thaw cycles, the strength loss of air-entrained concrete under triaxial compression load is lower than that of plain concrete.

The damage of concrete under triaxial compression load, biaxial compression load, and uniaxial compression load is caused by the transverse cracking. Compared with concrete specimen under uniaxial compression load, the existence of lateral compression stress $\sigma_{2}^{D}$ under biaxial compression will have inhibitory effect on lateral expansion or lateral 
cracking in the direction of $\sigma_{2}^{D}$, and the existence of lateral compression stresses $\sigma_{1}^{D}$ and $\sigma_{2}^{D}$ under triaxial compression will have inhibitory effect on lateral expansion or lateral cracking in the direction of $\sigma_{1}^{D}$ and $\sigma_{2}^{D}$. So the triaxial compression strength and biaxial compression strength of air-entrained concrete are higher than uniaxial compression strength, and the triaxial compression strength is higher than biaxial compression strength due to the fact that there are inhibitory effect in the direction of $\sigma_{1}^{D}$ and $\sigma_{2}^{D}$.

\section{Conclusions}

Based upon the test results in the study and the discussion on the experiment results, the following conclusions and recommendations can be got:

(1) For air-entrained concrete under triaxial compression load, the effect of the action of rapid freeze-thaw cycles did not change the failure mode; slant-shear failure caused by the splitting tensile strain along $\sigma_{1}^{D}$ direction was observed, and the angle between the crack and the direction of $\sigma_{3}^{D}$ was about $20^{\circ} \sim 30^{\circ}$. There were two cracks on $\sigma_{2}^{D}$ surface; the number of cracks on $\sigma_{3}^{D}$ surface was one or two, respectively.

(2) The triaxial compressive strength with all stress ratios is greater than the biaxial and uniaxial compressive strength after the same rapid freeze-thaw cycles; the increased percentage of triaxial compressive strength over biaxial compressive strength or uniaxial compressive strength is dependent on the middle stress.

(3) The triaxial compression strength of air-entrained concrete decreases as number of rapid freeze-thaw cycles increases. The reduction of triaxial compression strength of air-entrained concrete is slower than that of uniaxial and biaxial compression strength as number of rapid freeze-thaw cycles increases.

(4) The failure criteria taking account of the action of stress ratio and rapid freeze-thaw cycles in octahedral stress space were suggested.

\section{Competing Interests}

The authors declare that they have no conflict of interests.

\section{Acknowledgments}

This work was supported by the "Projects of International Cooperation and Exchanges" (Grant no. 51420105015), "Project Funded by China Postdoctoral Science Foundation" (Grant no. 2015M580576), "The Special Funds for Shandong Province Postdoctoral Innovative Projects" (Grant no. 201501008), and "Primary Research \& Development Plan of Shandong Province" (Grant no. 2016GSF122003). And the authors gratefully acknowledge the financial support.

\section{References}

[1] E. Özgan and S. Serin, "Investigation of certain engineering characteristics of asphalt concrete exposed to freeze-thaw cycles," Cold Regions Science and Technology, vol. 85, pp. 131136,2013

[2] B. Kucharczyková, Z. Keršner, and O. Pospíchal, "Influence of freeze-thaw cycles on fracture parameters values of lightweight concrete," Procedia Engineering, vol. 2, no. 1, pp. 959-966, 2010.

[3] B. B. Sabir, "Mechanical properties and frost resistance of silica fume concrete," Cement and Concrete Composites, vol. 19, no. 4, pp. 285-294, 1997.

[4] A. E. Richardson, K. A. Coventry, and S. Wilkinson, "Freeze/ thaw durability of concrete with synthetic fibre additions," Cold Regions Science and Technology, vol. 83-84, pp. 49-56, 2012.

[5] M. J. Setzer, "Micro-ice-lens formation in porous solid," Journal of Colloid and Interface Science, vol. 243, no. 1, pp. 193-201, 2001.

[6] G. Fagerlund, "The significance of critical degrees of saturation at freezing of porous and brittle materials," in Proceedings of the Conference on Durability of Concrete: ACI Symposium Sessions, pp. 13-65, American Concrete Institute, 1975.

[7] L. Petersen, L. Lohaus, and M. A. Polak, "Influence of freezingand-thawing damage on behavior of reinforced concrete elements," ACI Materials Journal, vol. 104, no. 4, pp. 369-378, 2007.

[8] W. Sun, Y. M. Zhang, H. D. Yan, and R. Mu, "Damage and damage resistance of high strength concrete under the action of load and freeze-thaw cycles," Cement and Concrete Research, vol. 29, no. 9, pp. 1519-1523, 1999.

[9] K. Z. Hanjari, P. Utgenannt, and K. Lundgren, "Experimental study of the material and bond properties of frost-damaged concrete," Cement and Concrete Research, vol. 41, no. 3, pp. 244$254,2011$.

[10] B. B. Sabir and K. Kouyiali, "Freeze-thaw durability of airentrained CSF concrete," Cement and Concrete Composites, vol. 13, no. 3, pp. 203-208, 1991.

[11] A. Gokce, S. Nagataki, T. Saeki, and M. Hisada, "Freezing and thawing resistance of air-entrained concrete incorporating recycled coarse aggregate: the role of air content in demolished concrete," Cement and Concrete Research, vol. 34, no. 5, pp. 799806, 2004.

[12] H.-S. Shang and Y.-P. Song, "Behavior of air-entrained concrete under the compression with constant confined stress after freeze-thaw cycles," Cement and Concrete Composites, vol. 30, no. 9, pp. 854-860, 2008.

[13] S. Chatterji, "Freezing of air-entrained cement-based materials and specific actions of air-entraining agents," Cement and Concrete Composites, vol. 25, no. 7, pp. 759-765, 2003.

[14] T. Pheeraphan and C. K. Y. Leung, "Freeze-thaw durability of microwave cured air-entrained concrete," Cement and Concrete Research, vol. 27, no. 3, pp. 427-435, 1997.

[15] H. Shang, Y. Song, and J. Ou, "Behavior of air-entrained concrete after freeze-thaw cycles," Acta Mechanica Solida Sinica, vol. 22, no. 3, pp. 261-266, 2009.

[16] A. Mahboubi and A. Ajorloo, "Experimental study of the mechanical behavior of plastic concrete in triaxial compression," Cement and Concrete Research, vol. 35, no. 2, pp. 412-419, 2005.

[17] C.-Z. Wang, Z.-H. Guo, and X.-Q. Zhang, "Experimental investigation of biaxial and triaxial compressive concrete strength," ACI Materials Journal, vol. 84, no. 2, pp. 92-100, 1987. 
[18] Y. P. Song, G. F. Zhao, F. Peng et al., "Strength behavior and failure criterion of steel fiber concrete under triaxial compressive stress," China Civil Engineering Journal, vol. 27, no. 3, pp. 14-23, 1994.

[19] L. K. Qin, Study on the strength and deformation of concrete under multiaxial stress after high-temperature of freeze-thaw cycling [Ph.D. thesis], Dalian University of Technology, Dalian, China, 2003 (Chinese).

[20] H.-S. Shang, Y.-P. Song, and L.-K. Qin, "Experimental study on strength and deformation of plain concrete under triaxial compression after freeze-thaw cycles," Building and Environment, vol. 43, no. 7, pp. 1197-1204, 2008.

[21] H. S. Shang and Y. P. Song, "Experimental study of strength and deformation of plain concrete under biaxial compression after freezing and thawing cycles," Cement and Concrete Research, vol. 36, no. 10, pp. 1857-1864, 2006.

[22] Y. Sun, B. Huang, J. Chen et al., "Characterization of triaxial stress state linear viscoelastic behavior of asphalt concrete," Journal of Materials in Civil Engineering, Article ID 04016259, 10 pages, 2016.

[23] L.-C. Wang and Y.-P. Song, "Mechanical behavior and failure criterion of the gangue-based haydite concrete under triaxial loading," Materials and Structures, vol. 48, no. 5, pp. 1419-1433, 2015.

[24] L.-C. Wang, "Multi-axial strength criterion of lightweight aggregate (LWA) concrete under the Unified Twin-shear strength theory," Structural Engineering and Mechanics, vol. 41, no. 4, pp. 495-508, 2012.

[25] K. Z. Hanjari, Load-carrying capacity of damaged concrete structures [Ph.D. thesis], Chalmers University of Technology, Gothenburg, Sweden, 2008.

[26] H. S. Shang, "Triaxial compressive strength of air-entrained concrete after freeze-thaw cycles," Cold Regions Science and Technology, vol. 91, no. 1, pp. 33-37, 2013.

[27] GB/T50082-2009, The Test Method of Long-Term and Durability on Ordinary Concrete, China Architecture \& Building Press, Beijing, China, 2009.

[28] ASTM International Committee C09 on Concrete and Concrete Aggregates, Standard Test Method for Resistance of Concrete to Rapid Freezing and Thawing, ASTM International, 2008.

[29] M. G. Li, Q. Zhang, J. Wang et al., "Large scale static and dynamic concrete hydraulic servo triaxial testing equipment," Journal of Dalian University of Technology, vol. 43, no. 6, pp. 812817, 2003 (Chinese).

[30] P.-Y. Lu, Y.-P. Song, and Z.-M. Wu, "Strength and deformation characteristics of concrete subjected to different loading rates combined with confined stress," Journal of Dalian University of Technology, vol. 41, no. 6, pp. 716-720, 2001.

[31] Y. P. Song, Failure Criteria and Constitutive Relations of Concrete, WaterPower Press, Beijing, China, 2002 (Chinese). 

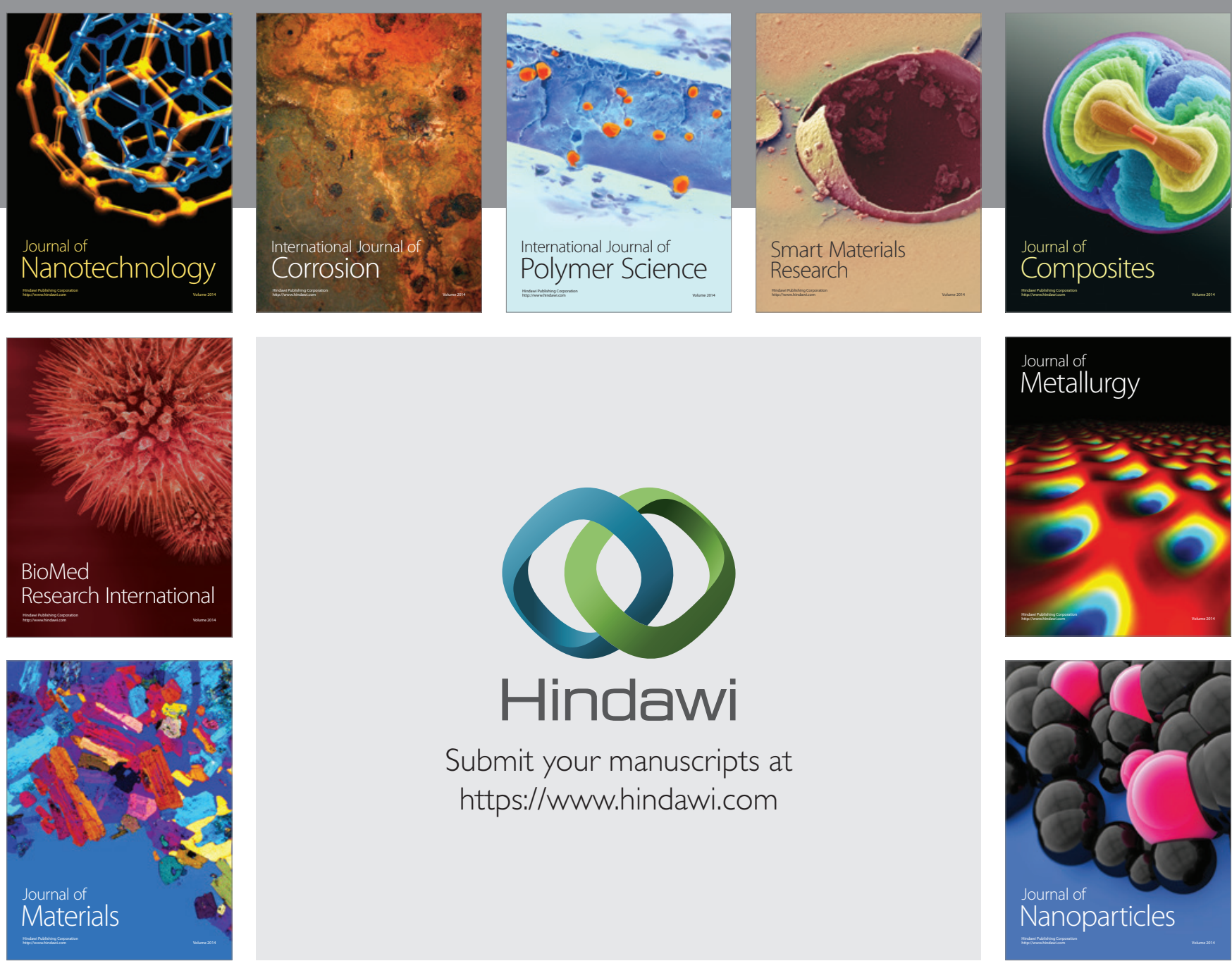

\section{Hindawi}

Submit your manuscripts at

https://www.hindawi.com

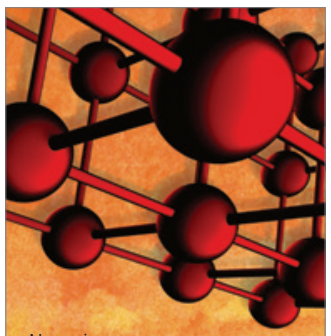

Materials Science and Engineering
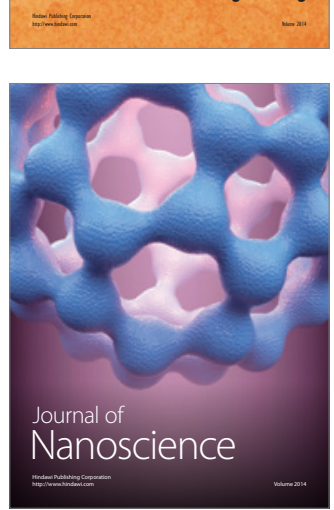
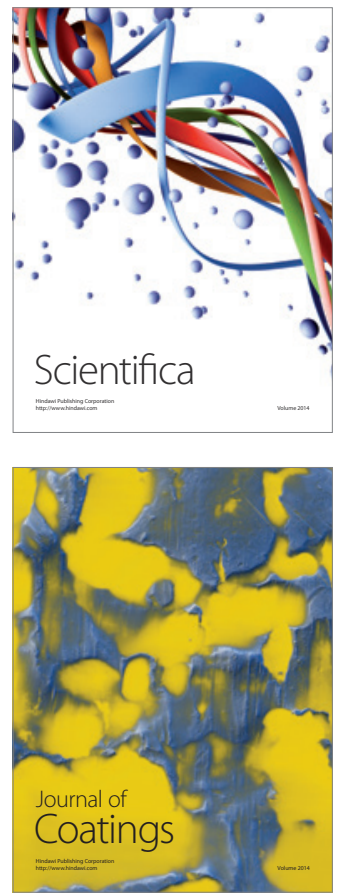
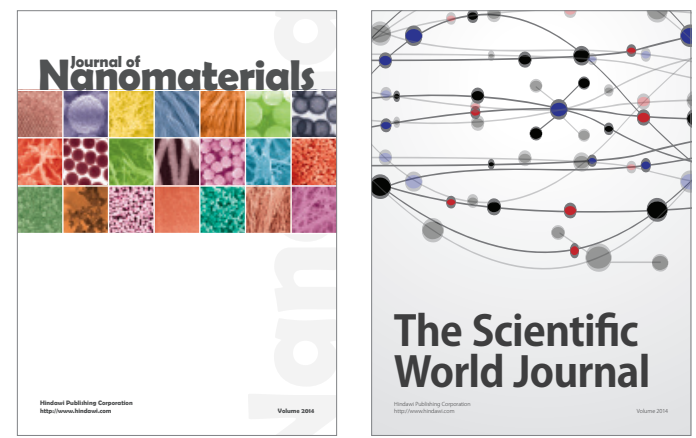

The Scientific World Journal
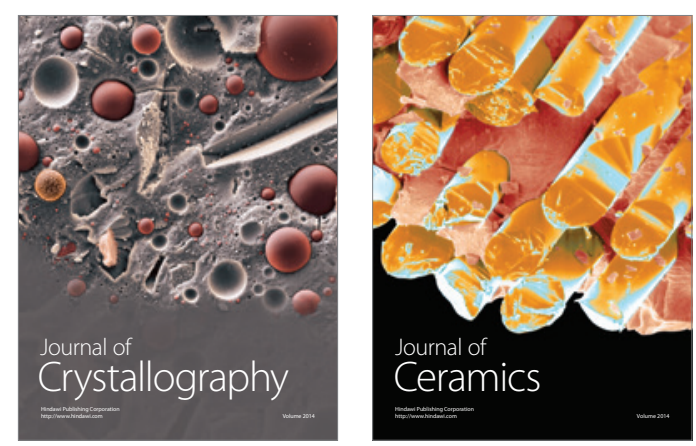
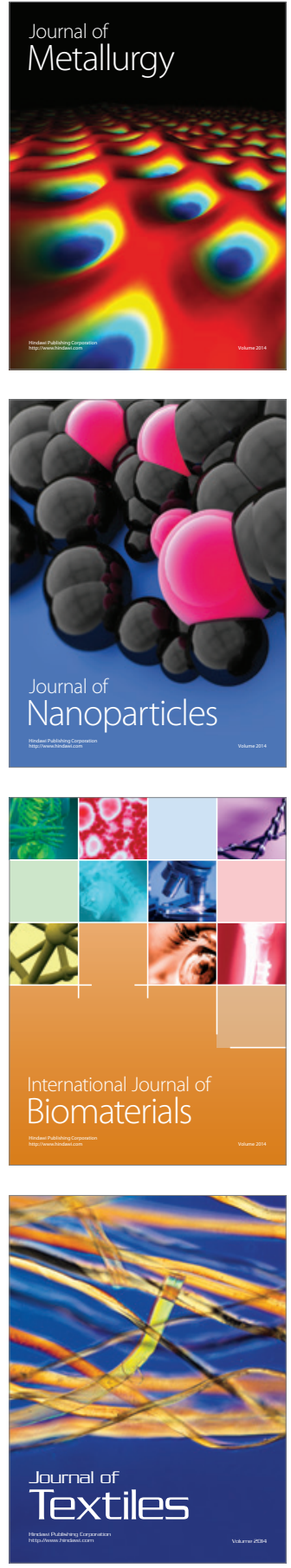